\title{
Description of mature larvae of the genus Austrelmis Brown from Argentina (Insecta: Coleoptera, Elmidae)
}

\author{
Miguel Archangelsky ${ }^{1 *}$, Nicolás Rafael Martínez Román ${ }^{1}$ and Verónica Manzo ${ }^{2}$ \\ ${ }^{1}$ Laboratorio de Investigaciones en Ecología y Sistemática Animal (LIESA), CIEMEP (CONICET-UNPSJB) Roca 780, 9200 Esquel, \\ Chubut, Argentina \\ 2 Instituto de Biodiversidad Neotropical (IBN), UNT-CONICET, Crisóstomo Álvarez 722, San Miguel de Tucumán (4000), \\ Tucumán, Argentina
}

Received 11 July 2016; Accepted 5 September 2016

\begin{abstract}
Mature larvae of two species of the riffle beetle genus Austrelmis Brown are described and illustrated for the first time: Austrelmis catamarcensis Manzo and Archangelsky and Austrelmis talampayensis Manzo and Archangelsky. A larval diagnosis for the genus is presented; larvae of both species are compared with each other and with two other previously described and illustrated Austrelmis larvae.
\end{abstract}

Key words: Riffle beetles / Elmidae / Neotropical / Argentina / larvae

\section{Introduction}

The genus Austrelmis Brown (1984), belongs to the family Elmidae, subfamily Elminae. It includes 26 species (Manzo and Archangelsky, 2015). Most of the species were originally described within the genus Macrelmis Motschulsky (1860), but Brown (1984) transferred all of them (except for the type species, Macrelmis dentata Motschulsky, 1860) to the new genus Austrelmis.

Austrelmis is endemic to the Neotropical Region, and seems to be an Andean element, since most of the known records are associated with the Andes Mountains and related foothills of western South America (Brown, 1984; Manzo and Archangelsky, 2012, 2015). Six species are known from Argentina: Austrelmis argentinensis Manzo and Archangelsky, 2015, Austrelmis catamarcensis Manzo and Archangelsky, 2015, Austrelmis patagonica Manzo and Archangelsky, 2012, Austrelmis robustus Manzo and Archangelsky, 2015, Austrelmis tafi Manzo and Archangelsky, 2015 and Austrelmis talampayensis Manzo and Archangelsky, 2015. Nevertheless, due to its vast distribution, it is expected that more new species will be collected and described in the future.

Larval knowledge of this genus is poor; only one description has been published so far. Hinton (1940) provided the generic characters of larvae of Austrelmis (as Macrelmis), and presented a description and illustrations of the mature larva of Austrelmis lata (Hinton, 1940).

*Corresponding author: hydrophilinae@gmail.com
More recently, Dejoux (1991) presented some illustrations of the mature larva of Austrelmis consors (Hinton, 1940) from Lake Titicaca, but no larval description accompanied the illustrations.

Given that Austrelmis larvae are very common in the Andean region, and elmids are important bioindicators, we consider it important to describe and illustrate in detail the mature larvae of two Argentinean species: A. catamarcensis and A. talampayensis, both from northwestern Argentina; we also provide comparative notes and morphometric measures that allow separation of mature larvae of both species; comparative notes with larvae of $A$. lata and $A$. consors (from Bolivia) are also included. A detailed generic diagnosis that will allow easy identification of other Austrelmis larvae at a generic level is also included.

\section{Materials and methods}

\section{Source of materials}

A. catamarcensis: Argentina: Catamarca Province: $4.5 \mathrm{~km}$ before Las Peladas, road to Paso San Francisco, $27^{\circ} 02^{\prime} \mathrm{S} \quad 68^{\circ} 04^{\prime} \mathrm{W}, 3925 \mathrm{~m}, 24-\mathrm{II}-2001,24-\mathrm{III}-2001$, 8-X-2001, M. Archangelsky coll.

A talampayensis: La Rioja Province, Parque Nacional Talampaya, Shimpa River, $29^{\circ} 45^{\prime} \mathrm{S} 67^{\circ} 48^{\prime} \mathrm{W}, 1300 \mathrm{~m}$, 3-VIII-1999, 4-VIII.1999, 2-XI.1999, M. Archangelsky coll. 


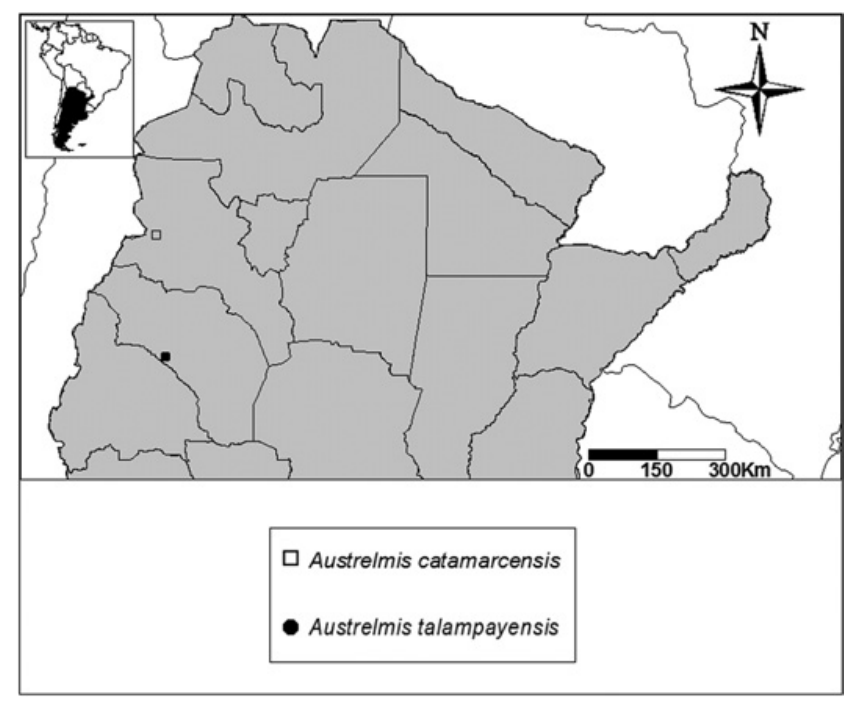

Fig. 1. Distributional map for Austrelmis species.

The nameless creek in Catamarca runs along a rock formation near Rd. 60 and is margined by high altitude grasses, typical of the dry Puna grassland environment. The creek is rather shallow, ranging between 15 and $40 \mathrm{~cm}$ in depth, its width ranging between 30 and $80 \mathrm{~cm}$. The bottom consisted of pebbles and sand; adults and larvae of $A$. catamarcensis were collected from mats of filamentous green algae and by removing the base of grasses submerged in the water.

The Shimpa River is a small creek running through a narrow steep-sided canyon, belonging to the Monte ecoregion. The creek is shallow, ranging between 5 and $30 \mathrm{~cm}$ in depth, and its width ranges between $30 \mathrm{~cm}$ and $1 \mathrm{~m}$; the bottom consisted of boulders, gravel and sand; adults and larvae of $A$. talampayensis were collected from mats of filamentous green algae.

Adults and larvae of A. catamarcensis and A. talampayensis were collected together at all dates; the distribution of both species is represented in Figure 1.

\section{Methods}

Larvae were killed and preserved in $75 \%$ ethyl alcohol. Larval specimens were cleared in warm lactic acid (six specimens of each species), dissected and mounted on glass slides with Hoyer's medium. Observations (up to $1000 \times$ ) were made using a Leica S6D dissecting microscope and a Leica DMLB compound microscope, both with a photographic camera attached. Photographs were assembled using the freeware program CombineZP (Hadley, 2010). Habitus pictures were taken from dry specimens; therefore, the color is darker than that of wet specimens. For morphometric information, five larvae of each species were measured. We follow the larval morphology nomenclature of Lawrence (1991) and Kodada and Jäch (2005).

A detailed description of the mature (last instar) larva of $A$. catamarcensis is provided; for A talampayensis only those characters that differ are listed. The materials studied are held in the Instituto de Biodiversidad Neotropical (IBN), Tucuman, Argentina, and in the larval collection of one of the authors (M.A.).

\section{Results}

\section{Diagnosis of mature larva of Austrelmis Brown}

Body elongate, subcylindrical, parallel sided; dorsal surface convex, with abdominal terga slightly gibbose on posterior $2 / 3$. Head exposed, not concealed by pronotum; clypeus concave, serrated; with a small lateral frontal tooth. Frontal lines Y-shaped, merging basally into a short coronal line. Stemmata closely aggregated into one ocular spot. Antenna with three antennomeres, antennal sensorium as long as or slightly longer than third antennomere. Mandibles symmetrical, with three apical teeth; prostheca long. Maxilla with large stipes and short palpus with four palpomeres; galea and lacinia well developed; galea entire, lacinia fused to stipes. Labium with large postmentum and short prementum, palpi with two palpomeres, inserted on a short palpiger. Prothorax with five ventral sclerites, one anterolateral pair, one lateral pair and one small posterior sclerite; coxal cavities closed. Meso- and metathorax with five ventral sclerites, one large anterior subpentagonal sclerite, and two smaller subrectangular sclerites on each side; coxal cavities open. Abdomen with pleural sclerites on segments I-VII; abdominal tergites with small gibbosities on posterior $2 / 3$ of each segment, margined by setiferous tubercles: abdominal sternites wider than long; segment IX with emarginated apical margin. Ventral operculum on abdominal segment IX subpentagonal. Abdominal hooks lacking teeth on inner margin.

\section{Austrelmis catamarcensis Manzo and Archangelsky, mature larva}

\section{Description}

Body (Figs. 2-4) elongate, rather narrow species, sides subparallel, widest at union between thorax and abdomen, abdominal segments narrowing towards posterior end; body subtriangular in cross-section. Color brown to reddish-brown. Length: $6.2-7.8 \mathrm{~mm}$; maximum width: $0.90-0.93 \mathrm{~mm}$.

Head capsule (Fig. 8) completely exposed, anterior margin of clypeus concave, serrated, with lateral corners slightly projected into a short tooth between clypeus and base of antenna. Dorsal surface with tubercles, rather dense on disc, becoming sparser towards lateral margins. Coronal line short, frontal lines long, extending to inner margin of antennal sockets. Frontoclypeal suture present, feeble. Gula large, subtrapezoidal, subequal in width to maxillolabial complex; basal margin wider, concave, distal margin narrower. Stemmata closely aggregated on each 

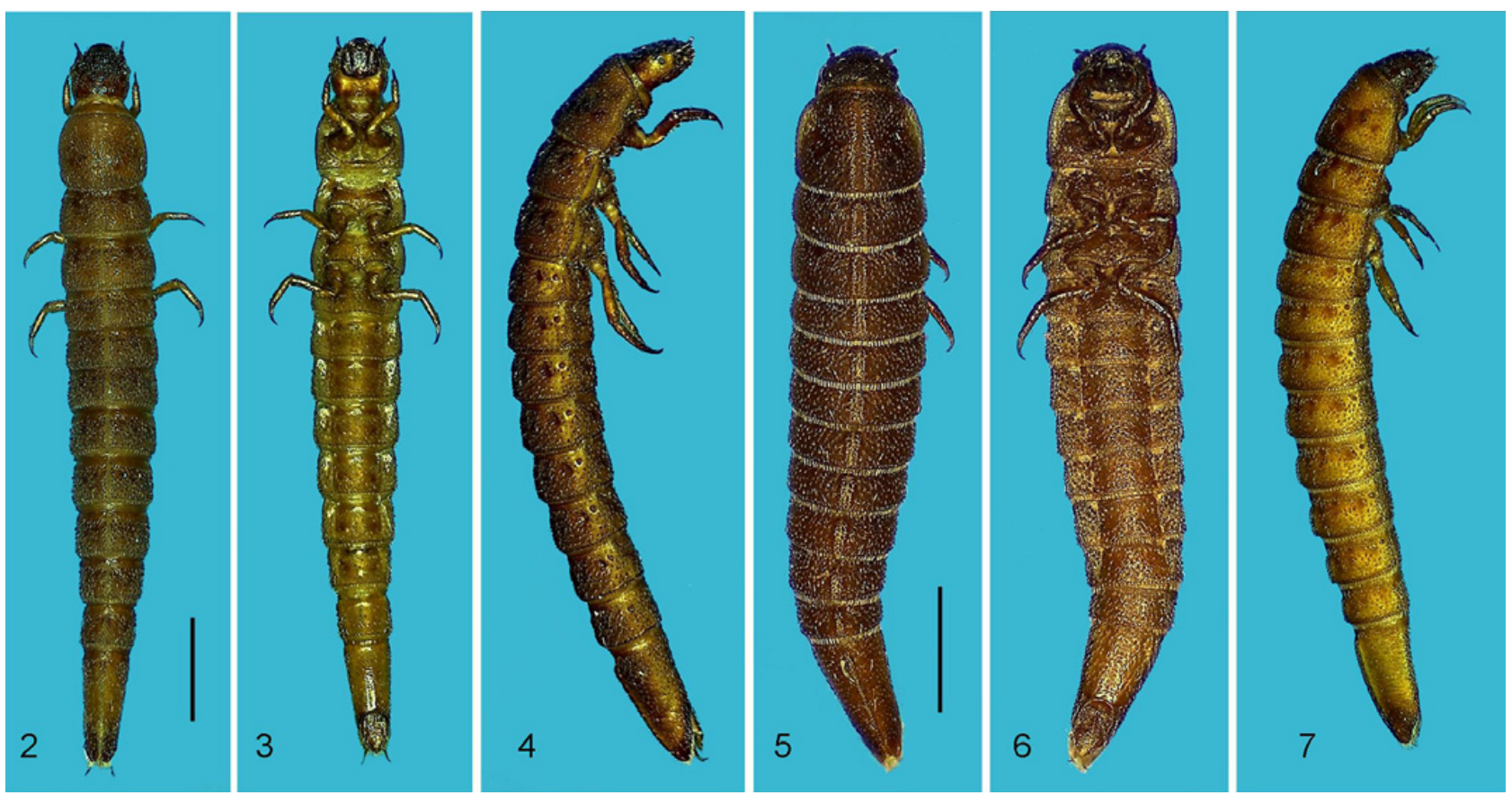

Figs. 2-7. Austrelmis mature larval habitus. 2- A. catamarcensis, dorsal view; 3- A. catamarcensis, ventral view; 4- A. catamarcensis, lateral view; 5- A. talampayensis, dorsal view; 6- A. talampayensis, ventral view; 7- A. talampayensis, lateral view. Scale bars: 1 mm.

side of head, closer to base of antenna than to posterior end of head capsule.

Labrum (Figs. 14 and 15) subrectangular, anterolateral corners rounded, each with three strong setae dorsally, outer two ramose. A transverse irregular band of strong setae arranged on dorsal surface at about distal third. Anteroventral margin with a row of seven ramose setae on each side, lateral ones larger than middle ones; rest of ventral surface covered by microtrichiae oriented mesally and posteriorly.

Antenna (Fig. 9) short, not projecting further than mandibles, with three antennomeres, located on anterolateral corners of head capsule. Basal antennomere (A1) short, slightly wider than long, bearing a crown of ramose setae. Second antennomere (A2) the longest, bearing three distal short setae and a short sensorium. Third antennomere (A3) the shortest, slightly shorter than sensorium, bearing a short apical seta.

Mandibles (Figs. 10 and 11) symmetrical, apex with three blunt teeth. Inner margin sharp dorsally, with one blunt retinaculum and inner margin almost straight behind it; ventral margin bearing a comb of sharp stout submarginal setae and fine cuticular projections. Prostheca present, large and ramose, oriented mesally and backwards. Outer margin of mandible with two stout ramose setae at about midlength.

Maxillae (Figs. 12 and 13) basally with transverse, narrow subtriangular cardo, bearing a short seta closer to outer margin. Stipes large, subrectangular, 1.9 times as long as wide; disc of stipes with several short ramose setae, becoming larger towards distal end; distal third with three stout longer setae arranged as follows: two close to outer base of palpus, third one close to inner base of palpus.
Lacinia and galea strongly sclerotized; lacinia subtriangular, partially fused to stipes, with several apical and subapical stout setae distally and on inner margin; galea entire, shorter than lacinia, bearing a group of stout distal setae. Palpus with four palpomeres, first palpomere the shortest, bearing a stout ventral seta; second palpomere twice as long as first, lacking setae; third palpomere slightly longer than second, with two apical setae, one on inner margin and one on outer margin; distal palpomere slightly longer than first, bearing several short apical sensilla.

Labium (Figs. 12 and 13) well developed, formed by a large postmentum and a short prementum. Postmentum 1.6 times longer than wide, slightly narrower basally; ventral surface with scattered short ramose setae at each side of midline, distal corners each with one long stout seta, two large ramose setae and one stout blunt short seta. Prementum short, less sclerotized than postmentum, wider than long, with two large ramose setae on disc and densely setose distal margin. Palpus with two palpomeres, palpifer present, well sclerotized; both palpomeres subequal in length; first palpomere bearing several short setae on outer apical corner; second palpomere narrower, bearing several apical sensilla.

Proventriculus (Fig. 24) equipped with strongly sclerotized teeth arranged as follows: one posterior row of elongated teeth forming a well-defined belt, preceded by four irregularly arranged rows of shorter rugulose teeth and an anterior belt of narrow sharp teeth; whole structure as long as wide. Gut content typical of a scraper, including numerous diatoms and rests of algae (Fig. 25).

Thorax (Figs. 2-4 and 16) strongly sclerotized; tergal plates with sagittal lines and with sparse small setiferous 

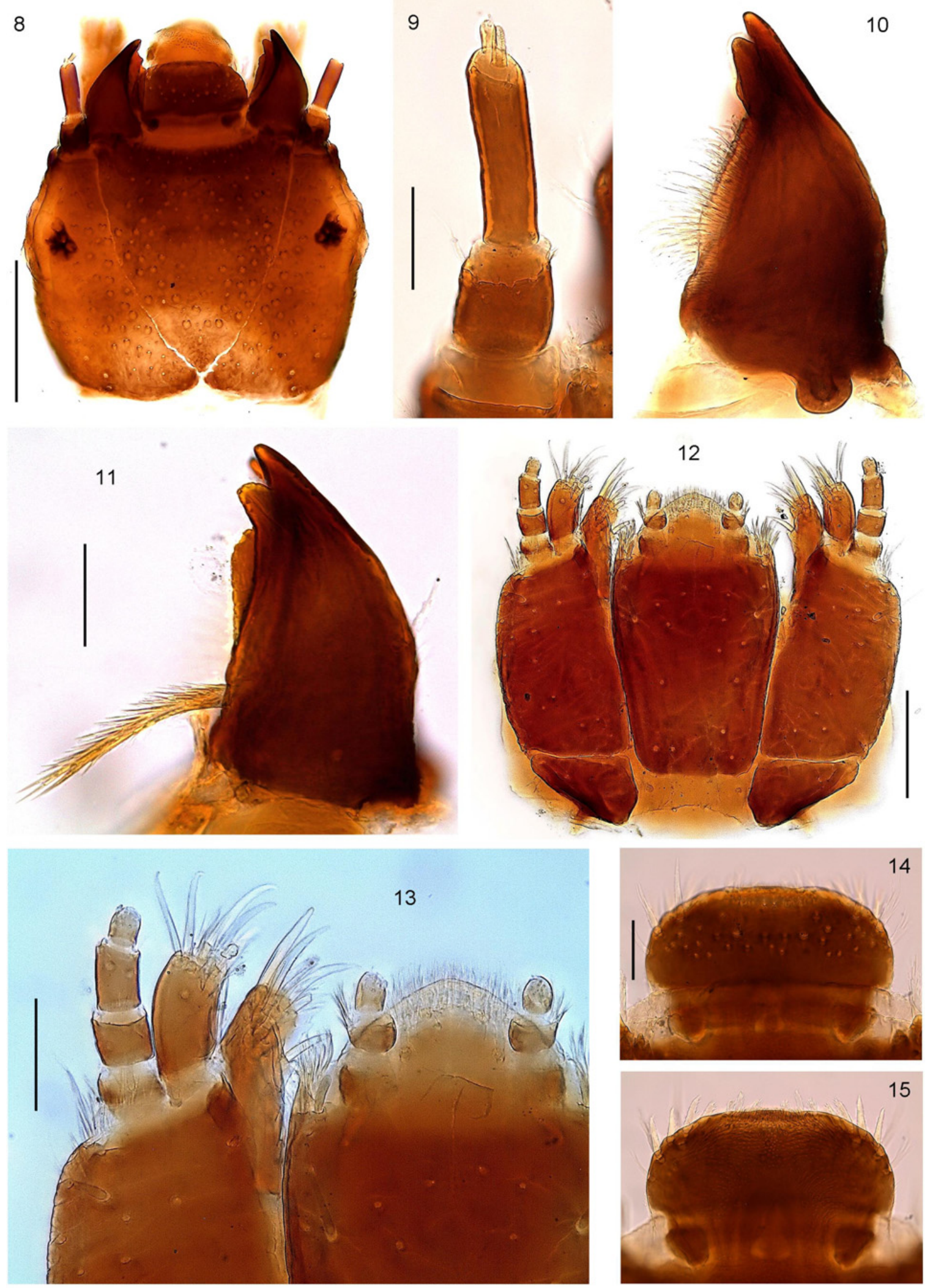

Figs. 8-15. A. catamarcensis, mature larva. 8- head capsule, dorsal view; 9- antenna, dorsal view; 10- mandible, ventral view; 11- mandible, dorsal view; 12- maxillolabial complex, ventral view; 13- maxillolabial complex, detail of distal end, ventral view; 14- labrum, dorsal view; 15- labrum, ventral view. Scale bars: Fig. 8: 0.25 mm; Figs. 9-11, 13-15: 0.05 mm; Fig. 12: 0.1 mm. 

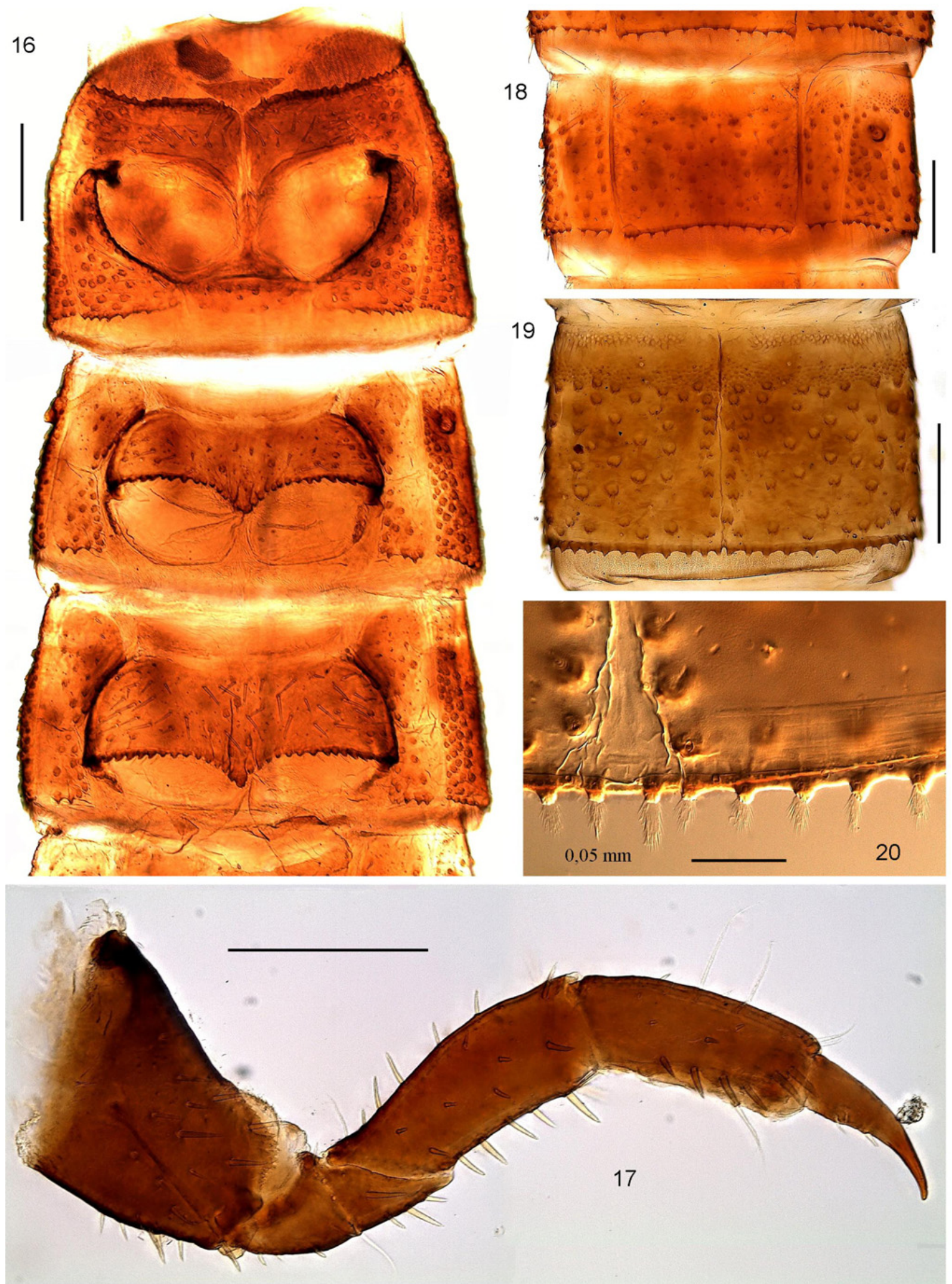

Figs. 16-20. A. catamarcensis, mature larva. 16- thorax, ventral view; 17- prothoracic leg, anterior view; 18- abdominal segment V, ventral view; 19- abdominal segment VIII, dorsal view; 20- detail of posterior setiferous projections of abdominal tergites, dorsal view. Scale bars: Figs. 16-19: 0.2 mm; Fig. 20: 0.05 mm. 

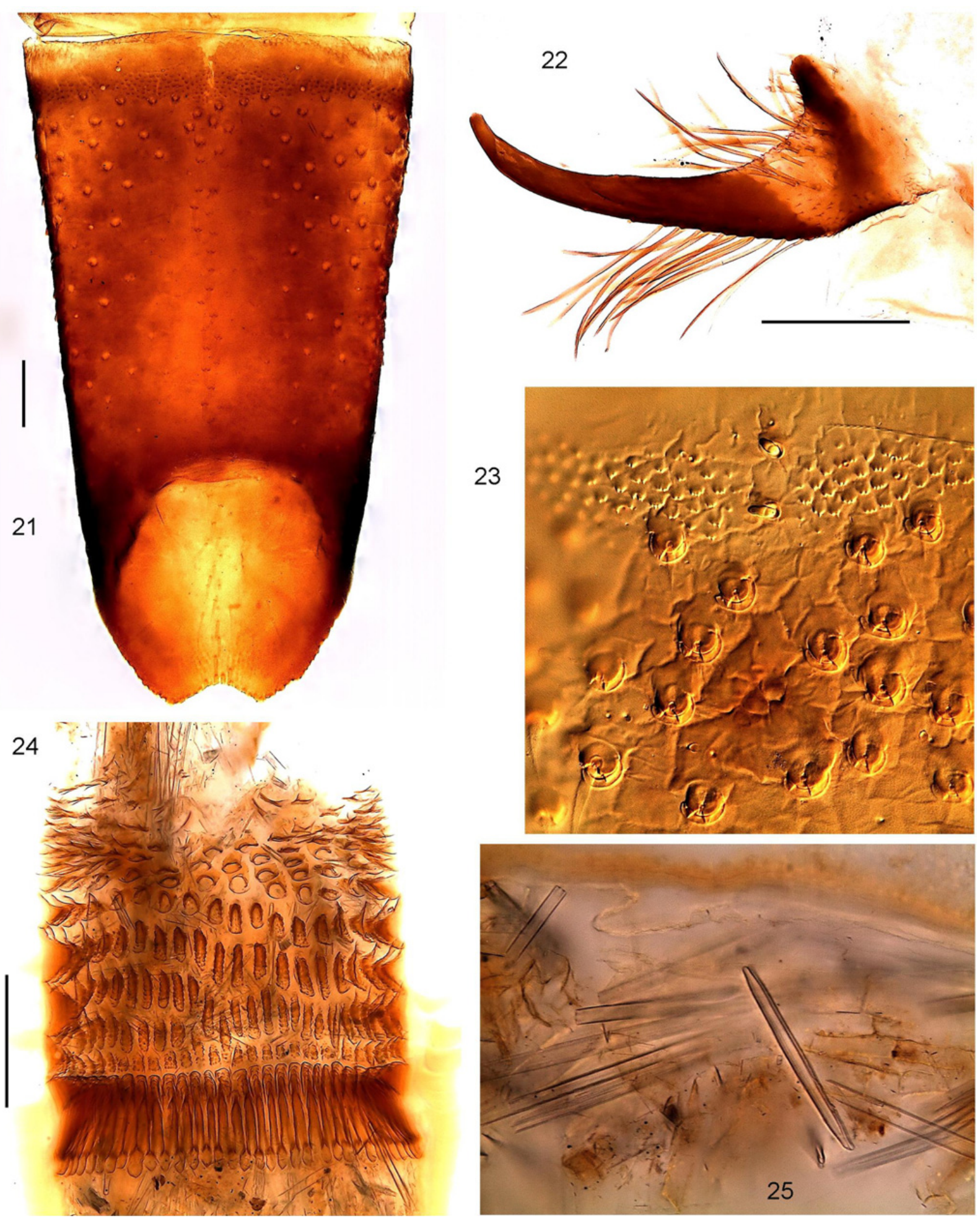

Figs. 21-25. A catamarcensis, mature larva. 21- abdominal segment IX, dorsal view; 22- hook of tracheal chamber; 23- abdominal tergite, detail of rugulose area; 24- proventriculus; 25- gut content. Scale bars: Figs. 21, 22 and 24: 0.1 mm.

tubercles not arranged in rows; prothorax longer than meso- and metathorax, all three segments subequal in width. Prothorax subtrapezoidal, wider basally, anterior corners feebly rounded; ventral region with five sclerites, two anterior subrectanguar sclerites anterior to procoxae, two subtriangular lateral sclerites and one small subpentagonal sclerite closing procoxal cavities and extending anteriorly between procoxae. Meso- and metathorax wider than long, each ventral region with five sclerites: one large anterior subpentagonal sclerite and two smaller 
subrectangular sclerites on each side; coxal cavities open. Mesothorax bearing a pair of lateral spiracles. Legs (Fig. 17) with coxa large, subtriangular; trochanter smaller, subtriangular; femur and tibia elongate, femur subequal to tibia in width; claw stout, shorter than tibia; prothoracic legs the shortest, metathoracic legs the longest.

Abdomen (Figs. 2-4, 18-23) strongly sclerotized, ninesegmented, tapering towards posterior end; segments I-VII with complete sagittal line, sagittal line of segment VIII incomplete, segment IX without sagittal line; segments I-VIII subequal in length, segment IX the longest, 3 times longer than segment VIII. All segments with a basal ring of rugulose sculpture, more developed dorsally. Terga with sparse small setiferous tubercles not arranged in rows except for those along midline (bordering sagittal lines when present), each tubercle bearing a small plumose seta. Pleural sclerites on segments I-VII, that of segment VII triangular; sternal plates subrectangular, wider than long, that of segment I widest, becoming narrower towards segment VII. Posterior margin of tergal and sternal plates of segments I-VIII with a row of short tubercles bearing plumose setae, lateral ones larger; tubercles separated by 1.5-2.0 times their width. Segment IX bearing a small dorsal keel with a row of tubercles, apex emarginated; distal end of sternal area with gill chamber covered by a subpentagonal operculum, covering a pair of long sharply pointed hooks; hooks slightly serrated at base, lacking teeth on inner margin. Spiracles present on segments I-VIII.

\section{Austrelmis talampayensis Manzo and Archangelsky, mature larva}

Body (Figs. 5-7) elongate, slightly wider. Color reddish brown. Length: $5.2-6.1 \mathrm{~mm}$; maximum width: 0.83-0.91 mm.

Head capsule (Fig. 26) with dorsal surface more densely tuberculated and strongly rugulose on basal half.

Labrum (Figs. 32 and 33) subrectangular, setation similar to that of $A$. catamarcensis.

Antenna (Fig. 27) similar to that of A. catamarcensis except for A1 as long as wide, or slightly longer than wide and $\mathrm{A} 2$ proportionally shorter.

Mandibles (Figs. 28 and 29) symmetrical, slightly wider basally; inner margin distinctly concave.

Maxillae (Figs. 30 and 31), cardo with distinctly rounded outer margins; lacinia and galea more slender; lacinia partly fused to stipes, reaching as far as distal margin of third palpomere; palpus slightly slender.

Labium (Figs. 30 and 31) with palpi longer than prementum.

Proventriculus (Fig. 43) with teeth arranged as in A. catamarcensis but the whole structure wider than long.

Thorax (Figs. 5-7, 34) proportionally wider; posterior ventral sclerite of prothorax larger, with anterior projection between coxae wider; posterior marginal setae of thoracic segments larger, flat, fan-like. Prolegs (Fig. 35) with femur slightly stouter and tibia more slender distally.
Abdomen (Figs. 5-7, 36-42) very similar to that of A. catamarcensis, basal rugulose areas of tergites and sternites more extended and more strongly marked. Setiferous projections of posterior margin on tergal and sternal plates more numerous and more closely arranged, separated by 1.0 times their width, those of sternal plates longer and sharp. Gibba on abdominal segments more prominent.

\section{Comparative notes}

Larvae of both species are very similar, but several differences, some morphometrical, are useful to tell them apart. Mature larvae of $A$. talampayensis are smaller (5.1-6.1 $\mathrm{mm}$ ) than those of $A$. catamarcensis $(6.2-7.8 \mathrm{~mm})$; the ratio of larval length/maximum width reveals that mature A. talampayensis larvae are slightly wider (ratio: 6.3-6.7) than those of $A$. catamarcensis (ratio: 6.9-8.4). The head capsule in A. talampayensis is more strongly rugulose on the basal half, and more densely tuberculated than in $A$. catamarcensis. The antennae show two morphological differences: the first is the ratio width A1/length A1, which is $1.2-1.3$ in $A$. catamarcensis and $0.9-1.0$ in $A$. talampayensis; the second is the ratio length A2/length A1, which is $2.3-2.4$ in $A$. catamarcensis and 1.7-2.0 in A. talampayensis. The mandibles are slightly narrower basally in $A$. catamarcensis (ratio length/width: 1.5-1.6) than those of $A$. talampayensis (ratio: 1.3-1.4); also, the inner margin of the mandible in $A$. talampayensis is distinctly concave, while in A. catamarcensis it is almost straight. The maxillae are very similar; the most distinctive difference is the length of the lacinia, which reaches as far as the distal margin of the third palpomere in A. talampayensis, while in A. catamarcensis it reaches the base of the third palpomere. The thorax and abdomen are also similar, the most obvious characteristic in which they differ are the basal rugulose areas of the thoracic and abdominal plates (both dorsal and ventral), which are more strongly marked and extended in A. talampayensis, and the length of the posterior setiferous projections of the abdominal sternites, longer and more numerous in A. talampayensis.

The description of A. lata by Hinton (1940) presents all the diagnostic characters of Austrelmis, nevertheless it is difficult to make a detailed comparison of larvae of A. catamarcensis and A. talampayensis with those of A. lata. From Hinton's description and illustrations, only a few differences could be found: 1- the cardo in A. lata is slender and much wider than the stipes (broader and as wide as the stipes in A. catamarcensis and A.talampayensis); 2- the inner margin of the mandible is almost straight in A. lata, similar to that of A. catamarcensis (concave in A. talampayensis); 3- the rugulose area of the thoracic and abdominal sclerites in A. lata is restricted to the basal $1 / 4$ or $1 / 6$, this is also more similar to what is observed in A. catamarcensis (in A. talampayensis this rugulose area is about $1 / 2$ or more); 4 - the setiferous projections on the posterior margin of the tergal plates in $A$. lata are 

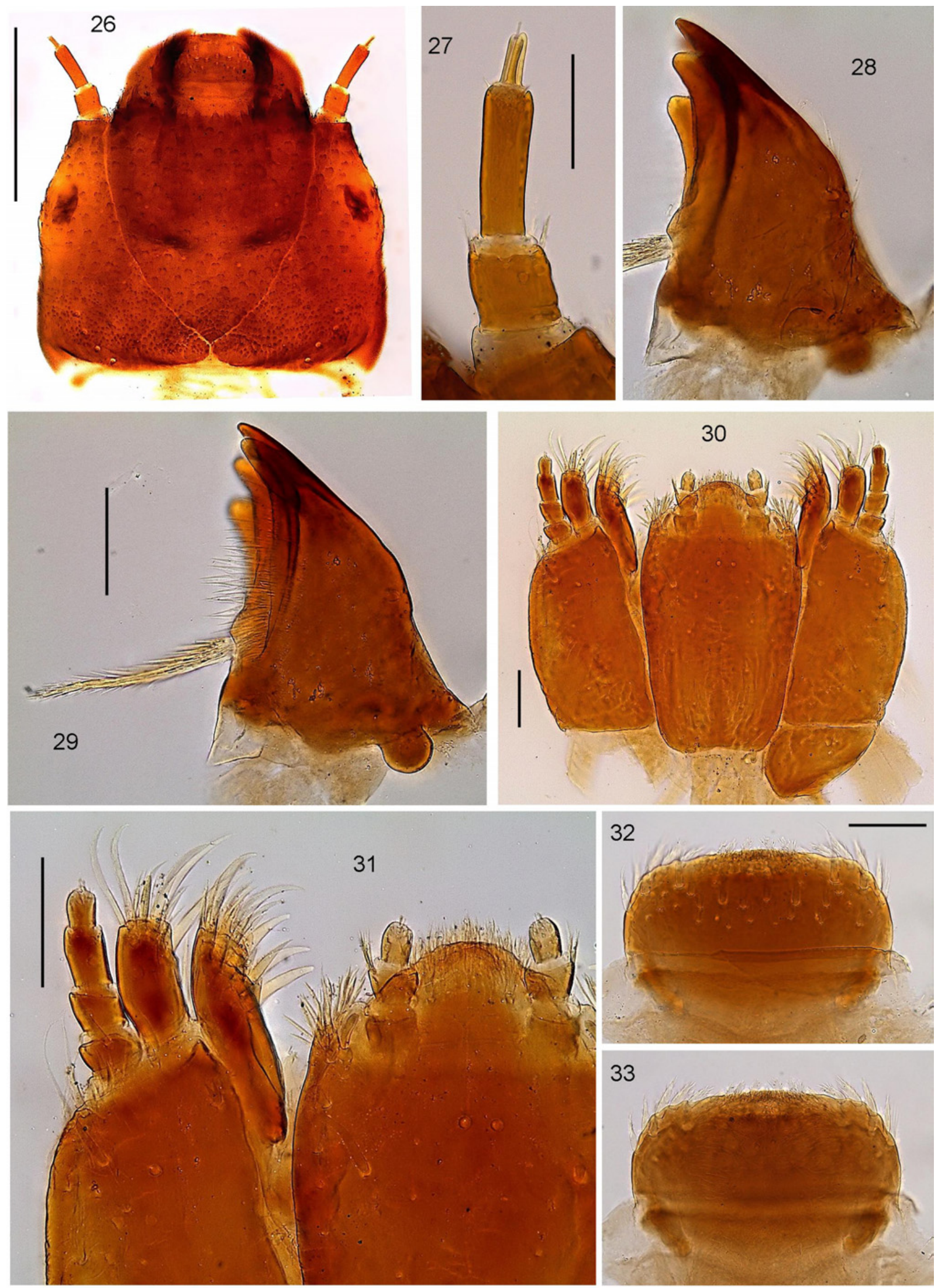

Figs. 26-33. A talampayensis, mature larva. 26- head capsule, dorsal view; 27- antenna, dorsal view; 28- mandible, dorsal view; 29- mandible, ventral view; 30- maxillolabial complex, ventral view; 31- maxillolabial complex, detail of distal end, ventral view; 32- labrum, dorsal view; 33- labrum, ventral view. Scale bars: Fig. 26: 0.25 mm; Figs. 27-33: 0.05 mm. 

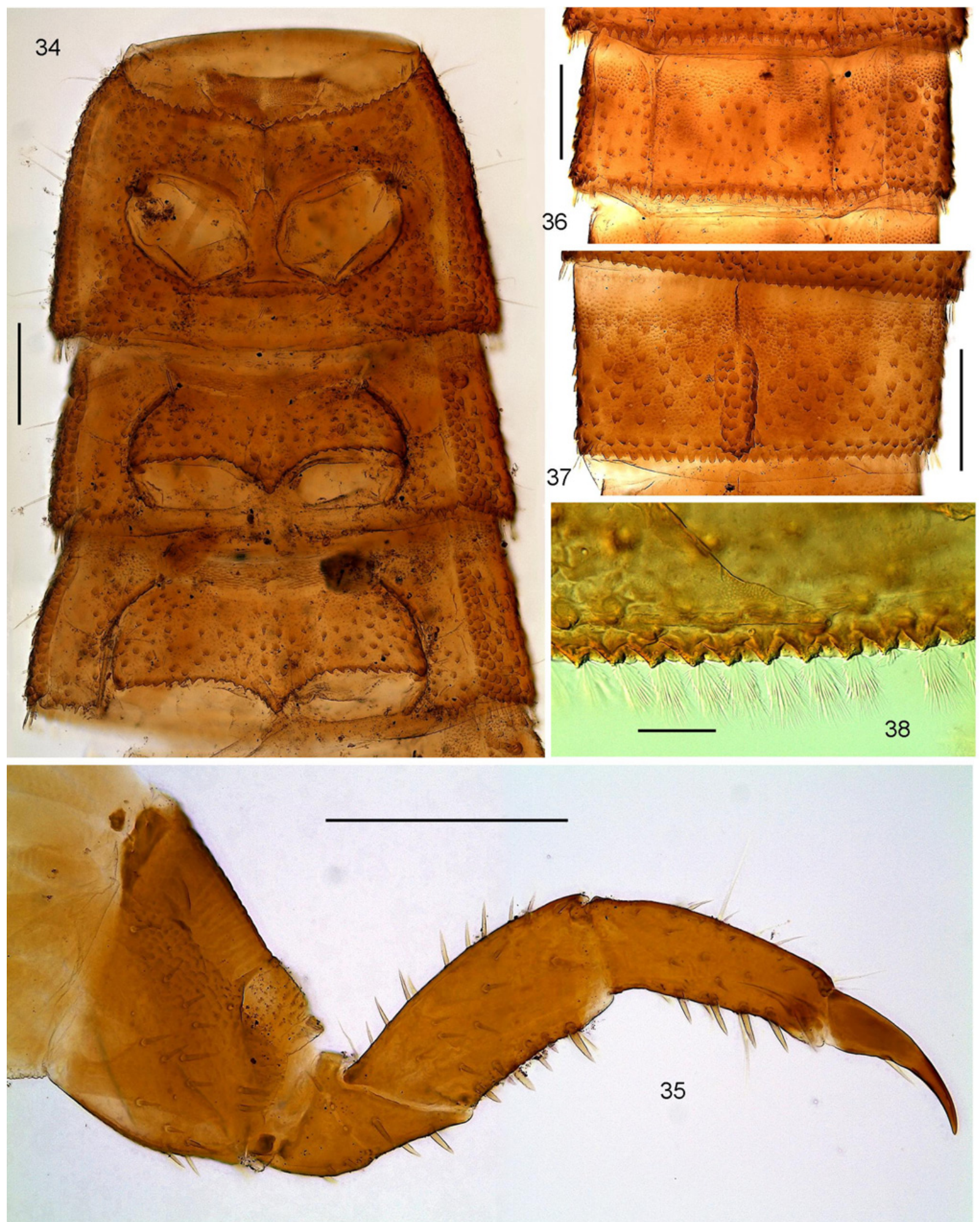

Figs. 34-38. A. talampayensis, mature larva. 34- thorax, ventral view; 35- prothoracic leg, anterior view; 36- abdominal segment V, ventral view; 37- abdominal segment VIII, dorsal view; 38- detail of posterior setiferous projections of abdominal tergites, dorsal view. Scale bars: Figs. 34-37: $0.2 \mathrm{~mm}$; Fig. 38: $0.05 \mathrm{~mm}$.

numerous and separated by 1.0 times their width, this is similar to what is observed in A. talampayensis (in $A$. catamarcensis these setae are less numerous and separated by 1.5-2.0 times their width); 5- mature larvae of $A$. lata are similar in length $(7.0 \mathrm{~mm})$ to those of A. catamarcensis, those of A. talampayensis are smaller (5.1-6.1 mm). In the illustrations provided by Hinton (1940, Fig. 72) and Dejoux (1991, Fig. 7), the ventral 

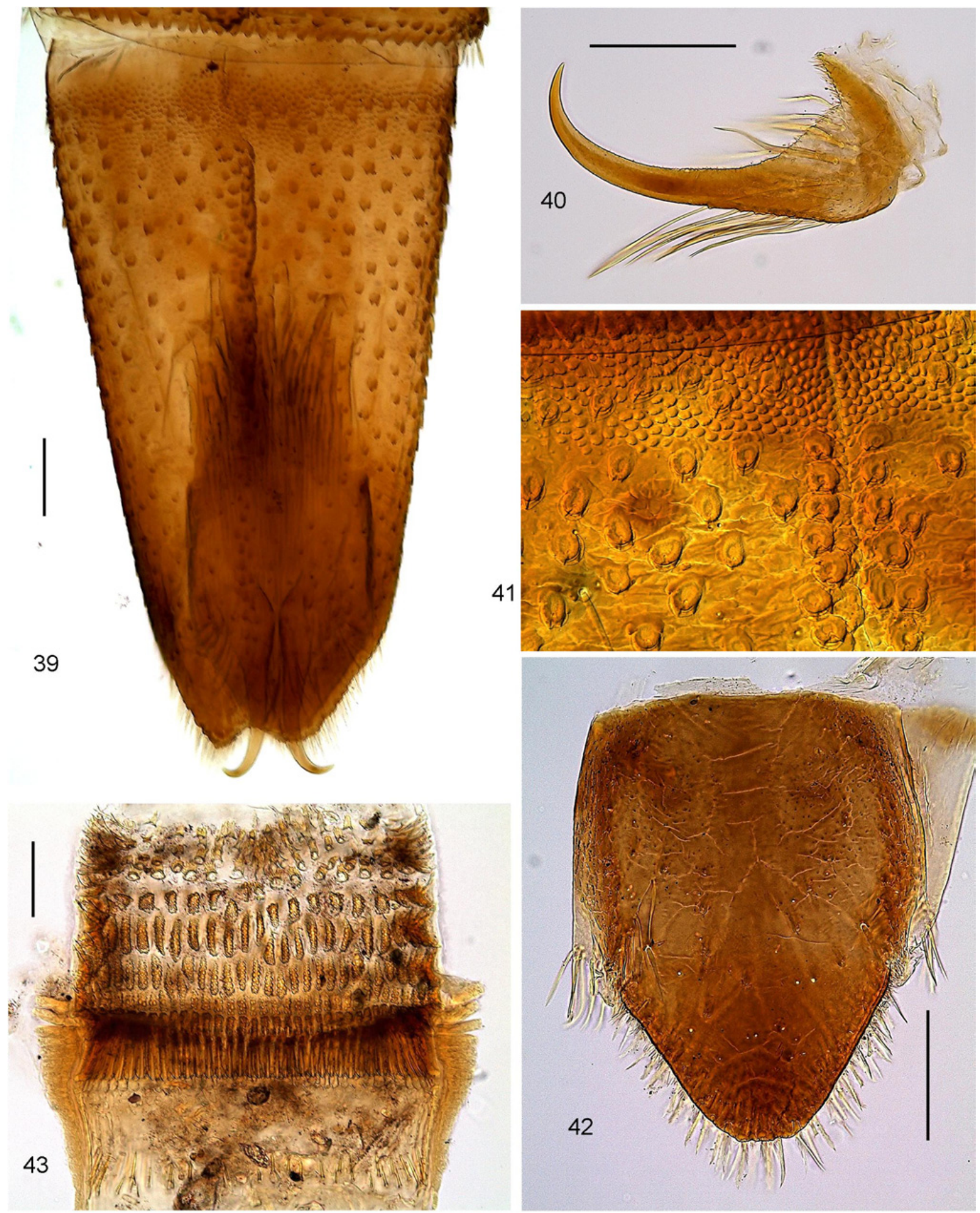

Figs. 39-43. A. talampayensis, mature larva. 39- abdominal segment IX, dorsal view; 40- hook of tracheal chamber; 41- abdominal tergite, detail of rugulose area; 42- operculum of tracheal chamber; 43-proventriculus. Scale bars: Figs. 39 and 40, 42 and 43 : 0.1 mm.

region of the meso- and metasternum appear as having six sclerites, two anterior and two on each side; the two anterior sclerites probably represent just one sclerite, which has an anterior fold, as is seen in $A$. catamarcensis and A. talampayensis (Figs. 16 and 34).
The illustrations of $A$. consors presented by Dejoux (1991) are not accompanied by a description, and only a couple of differences could be observed: 1- the inner margin of the mandible is almost straight, as in A. lata and A. catamarcensis (concave in A. talampayensis); 2- the 
mature larva of $A$. consors is larger than the other larvae (approximately $8.0 \mathrm{~mm}$ ).

From our observations, it seems clear that all known mature larvae of Austrelmis are rather similar morphologically, but several characters related to the sculpture and tubercles are useful to differentiate among them; additionally, several morphometric characters are informative, and should be considered in future larval descriptions of this genus. This could allow easy identification of larvae at specific level, and would be an important tool for those performing ecological and environmental studies in the region.

Acknowledgements. N. Martínez Román thanks the National Council of Scientific Research (CONICET, Argentina) for an internal fellowship. This research was partially supported by CONICET through PIP 0568/98 for the study of biodiversity and conservation of National Park Talampaya. This is contribution \#127 from LIESA.

\section{References}

Brown H.P., 1984. Neotropical dryopoids, III. Major Nomenclatural changes affecting Elsianus Sharp and
Macrelmis Motschulsky, with checklists of species (Coleoptera: Elmidae: Elminae). Coleopts. Bull., 37, 121-129.

Dejoux D., 1991. Los insectos. In: Dejeux C. and Iltis A. (eds.), El Lago Titicaca: Síntesis del Conocimiento Limnológico Actual, Orstrom \& Hisbol, La Paz, Bolivia, 371-386.

Hadley A., 2010. CombineZP. Available online at: http:// www.hadleyweb.pwp.blueyonder.co.uk.

Hinton H.E., 1940. The Percy Sladen Trust expedition to Lake Titicaca in 1937 under the leadership of Mr. H. Cary Gilson. VII. The Peruvian and Bolivian species of Macrelmis Motsch. (Coleoptera, Elmidae). Linnean Soc. London, Series 3, 1, 117-147.

Kodada J. and Jäch M.A., 2005. Elmidae. In: Beutel R.G. and Leschen R.A.B. (eds.), Coleoptera, Beetles, Vol. 1. Morphology and Systematics (Archostemata, Adephaga, Myxophaga, Polyphaga Partim), Walter de Gruyter, Berlin, 471-496.

Lawrence P.A., 1991. Order Coleoptera. In: Stehr F.W. (ed.), Immature Insects, Vol. 2, Kendall/Hunt, Dubuque, Iowa, 144-183.

Manzo V. and Archangelsky M., 2012. Two new species of Elmidae (Coleoptera) from Argentina. Zootaxa, 3478, 267-281.

Manzo V. and Archangelsky M., 2015. Austrelmis Brown (Coleoptera: Byrrhoidea: Elmidae) from Argentina: five new species. Zootaxa, 4058, 403-416.

Motschulsky V., 1860. Insectes des Indes orientales, et de contrées analogues. Etud. Entomol., 8, 25-118. [as 1959]. 